\title{
Ironic effects of performance are worse for neurotics
}

Barlow, M.D.; Woodman, Tim; Gorgulu, R.; Voyzey, R.M.

\section{Psychology of Sport and Exercise}

\author{
DOI: \\ 10.1016/j.psychsport.2015.12.005
}

Published: 21/12/2015

Peer reviewed version

Cyswllt i'r cyhoeddiad / Link to publication

Dyfyniad o'r fersiwn a gyhoeddwyd / Citation for published version (APA):

Barlow, M. D., Woodman, T., Gorgulu, R., \& Voyzey, R. M. (2015). Ironic effects of performance are worse for neurotics. Psychology of Sport and Exercise, 24, $27-37$.

https://doi.org/10.1016/j.psychsport.2015.12.005

\footnotetext{
Hawliau Cyffredinol / General rights

Copyright and moral rights for the publications made accessible in the public portal are retained by the authors and/or other copyright owners and it is a condition of accessing publications that users recognise and abide by the legal requirements associated with these rights.

- Users may download and print one copy of any publication from the public portal for the purpose of private study or research.

- You may not further distribute the material or use it for any profit-making activity or commercial gain

- You may freely distribute the URL identifying the publication in the public portal ?
}

Take down policy

If you believe that this document breaches copyright please contact us providing details, and we will remove access to the work immediately and investigate your claim. 
1 Running head: NEUROTICISM MODERATES IRONIC EFFECTS

Article accepted in its current form in Psychology of Sport and Exercise:

Barlow, M., Woodman, T., Gorgulu, R., \& Voyzey, R. (2016). Ironic effects of performance are worse for neurotics. Psychology of Sport \& Exercise (in press). doi:10.1016/j.psychsport.2015.12.005

Ironic effects of performance are worse for neurotics Gwynedd, LL57 2DG, UK. e-mail: m.barlow@bangor.ac.uk.

24 Date of submission: 8th July 2015

25 Date of resubmission: $6^{\text {th }}$ November 2015 


\section{Abstract}

Objectives: To conduct the first examination of neuroticism as a predictor of (1) the incidence of what Wegner $(1989,2009)$ terms ironic processes of mental control and (2) the precision of ironic performance errors under high- and low-anxiety conditions. Design: Across two studies we employed a repeated-measures design. task, under high-anxiety and low-anxiety conditions, participants gained maximum points for hitting a target zone and fewer points for hitting a designated non-ironic error zone.

Additionally, we instructed participants to be particularly careful not to hit a designated ironic error zone, because such hits would score minimum points.

Results: Across both studies within-subjects moderation analyses revealed a consistent moderating effect of neuroticism on the incidence of ironic errors in the highanxiety condition. Specifically, when anxious, neurotics displayed a significant increase in ironic performance error and a significant decrease in target hits. Importantly, non-ironic error did not differ across anxiety conditions. Additionally, Study 2 results revealed that neuroticism moderated the precision of ironic errors when anxious. Specifically, when anxious, neurotics' ironic error zone hits were significantly farther from the target zone and significantly farther into the ironic error zone than their relatively emotionally stable counterparts' errors.

Conclusion: We provide the first evidence that neuroticism moderates both the incidence and precision of ironic performance errors. These results will enable practitioners in coaching environments to make evidence-based predictions and interventions regarding which individuals are most prone to ironic performance breakdown when anxious.

Keywords: anxiety, ironic error, neuroticism, football, darts, stress. 
Ironic effects of performance are worse for neurotics

The greatest mistake you can make in life is to be continually fearing you will make one (Elbert Hubbard, 1927, p. 94)

Bill is a PGA tour golfer; he is also a worrier and most aspects of Bill's life are characterized by frequent concerns. So it was unsurprising that Bill felt anxious as he placed his golf ball on the $18^{\text {th }}$ tee, knowing that he needed only to make par to secure victory. Bill recognized that the biggest threat on this final hole was the lake to the right of the fairway. As Bill readied himself to take his tee shot he said to himself, "Right, whatever you do, just don't slice the ball into the lake." As soon as Bill hit the ball, he knew; he knew he'd hit the one shot he was trying to avoid; he then saw the splash of water as confirmation of his worst fear. He knew immediately that his chances of victory were lost in the water. As this example demonstrates, under pressure certain individuals exhibit not just a generalized decrease in performance but rather a decrease in performance that is precisely counter-intentional. Wegner's $(1989,1994,1997,2009)$ theory of ironic processes of mental control was developed with the aim of understanding counter-intentional error. To date researchers have given relatively little research attention to Wegner's theory in a performance domain. This may be in part due to the expressed reservations (e.g., Hall, Hardy, \& Gammage, 1999) that Wegner's theory offers little over and above more established theories of stress-performance such as cognitive processing (Baumeister, 1984; Masters, 1992), attentional control (Eysenck, Derakshan, Santos, \& Calvo, 2007), and catastrophe models (Hardy, 1990; Hardy, Mullen \& Jones, 1996). However, this reservation is somewhat surprising given that the alternate established theories cannot adequately explain why, under pressure, certain performers make errors that are ironic in nature; that is, a performance breakdown that is precisely counterintentional (Janelle, 1999).

Wegner's theory of ironic processes of mental control asserts that "the ironies of mental life are not just happenstance examples of the frailty of human endeavors but rather 
1 logically arise due to the nature of mental control" (Wegner, 1994, p. 34). Specifically,

2 foundational to Wegner's theory is the premise that mental control requires two processes in

3 order to work effectively. First, the cyclical operating process carries out intentional, effortful

4 regulation by consciously searching for, and directing the individual toward, mental contents

5 that will yield a desired outcome or intended emotional state; known as the desired state. It is

6 through active engagement in this mentally demanding search that regulation will most likely

7 be maintained and the desired state will be reached. Second, the monitoring process

8 subconsciously searches for mental contents that indicate a failure to achieve the desired

9 state. If this monitor identifies any such failures it reactivates the operating process with the

10 aim of filling the mind with mental contents that are relevant to the desired state, and thus

11 reestablishing a regulated mind. Both processes work within one control system and operate together as part of a feedback loop that, under normal circumstances, provides effective 13 mental control (Wegner, 1994).

Wegner (1994) suggested that these very processes that enable an individual to exercise mental control are also, under certain conditions, responsible for undermining intentional mental control. Specifically, under conditions of mental load (e.g., anxiety), some of the cognitive space that is required for the effortful operating process to operate effectively is consumed by the mental load. As such, the operating process becomes less effective at introducing the desired content into awareness. Conversely, the functioning of the monitoring

20 process - because it is both unconscious and not easily interrupted - remains largely

21 unaffected under mental load. Thus, under mental load the monitoring process becomes more salient and the search for thoughts or sensations that conflict with the desired state are enough to bring them into consciousness and thereby undermine the intended control (Wegner, Erber,

$24 \&$ Zanakos, 1993). This is ironic because the (monitoring) process that normally ensures that the to-be-avoided state is kept at bay is the very process that increases an individual's 
1 awareness of - and thus likelihood of bringing about - the to-be-avoided state (Woodman,

2 Barlow, \& Gorgulu, 2015). The result is that one is more likely to do specifically what one

3 intends not to do, when one least wants to do it.

Several studies have provided evidence in support Wegner's theory (e.g., Binsch,

5 Oudejans, Bakker \& Savelsbergh, 2009; Dugdale \& Eklund, 2003; Wegner, Ansfield, \&

6 Pilloff, 1998; Woodman et al., 2015). For example, in a dart throwing task, Oudejans, Binsch,

7 and Bakker (2013) demonstrated that the combination of negatively worded instructions ("Be

8 careful not to hit...”) and induced anxiety (participants threw their darts whilst positioned

9 high on a climbing wall) significantly increased the proportion of darts landing in the

10 specifically to-be-avoided zone when compared to negatively worded instructions under

11 conditions of low-anxiety (participants threw their darts whilst positioned at a low-level on a

12 climbing wall). However, manipulating height-off-the-ground is clearly not an ecologically

valid stressor in a dart-throwing task. Interestingly, other studies have failed to demonstrate

effects consistent with Wegner's postulate. Indeed, across two studies, using a golf putting

task, de la Peña, Murray and Janelle (2008) revealed findings that were seemingly counter to

Wegner's theory. Specifically, when instructed 'not to putt long' or 'not to putt short'

participants compensated by putting significantly shorter or longer respectively. To explain

their results, which are in direct contrast to the prediction from Wegner's theory, de la Peña et

al. (2008) proposed the implicit overcompensation hypothesis (see also Russell \& Grealy,

2010; Toner, Moran, \& Jackson, 2013). de la Peña et al. (2008) argued that the negatively

worded self-instruction "don't putt it short" subconsciously exaggerates the negative connotation (i.e., "leaving the putt short is a failure") thus activating an overriding implicit counter message (i.e., "to avoid failure, it is better to err on the side of putting too long").

This implicit counter message generates an implicit command that guides movement execution under the notion that, in this example, it is better to overshoot the hole. 
Researchers have suggested that such equivocal results regarding the incidence, or not, of ironic performance effects may be attributed to a failure to manipulate anxiety (e.g., de la Peña et al., 2008; Woodman et al., 2015). Additionally, a failure to differentiate clearly between ironic and non-ironic error (e.g., Dugdale \& Eklund, 2002; Wegner, Ansfield \& Pilloff, 1998) has hampered the research examining ironic processes in performance settings: a limitation that has only recently been addressed by Woodman et al. (2015).

It is also worth considering factors beyond methodological limitations that may lead to such equivocal findings. Indeed, a growing body of evidence indicates that under specific environmental conditions (e.g., anxiety), personality may exert differential effects on performance (see Roberts \& Woodman, 2015). Thus, it is a theoretical shortcoming that previous research in this area has failed to consider personality as a potential moderating factor on the incidence of ironic performance errors. Since Wegner proposes that ironic errors occur when cognitive load occupies the critical mental capacity required to maintain the salience of the operating process, examining personality traits that are associated with elevated cognitive load is theoretically the most natural starting point for this line of investigation.

In this regard neuroticism is a personality trait that is worthy of research attention regarding its potential moderating role in the incidence of ironic performance errors (cf. Roberts \& Woodman, 2015; Woodman et al., 2015). Neuroticism is a broad dimension of personality - appearing in both the Big Five (Costa \& McCrae, 1987) and Giant 3 (Eysenck \& Eysenck, 1985) - characterized by the tendency to experience negative, distressing emotions (Costa \& McCrae, 1987), anxiety (Watson \& Clark, 1984), and a lack of emotional stability (Eysenck \& Eysenck, 1985). Research suggests that neurotic individuals experience stress and anxiety more frequently (Bolger \& Schilling, 1991), demonstrate greater sensitivity to criticism and negative stimuli (O’Sullivan, Zuckerman, \& Kraft, 1998; Tellegen, 1985), 
1 have lower self-confidence (Bandura, 1977), and have larger negative reactions to anxiety

2 (Bolger \& Zuckerman, 1995; Ormel \& Wohlfarth, 1991). Indeed, research has shown

3 neuroticism to be an undesirable trait in relation to successful performance in sport (Davis \&

4 Mogk, 1994; Silva, Shultz, Haslam, Martin, \& Murray, 1985).

The neurotic individual's emotional experience in everyday life is such that cognitive space is consumed by generalized worries and concerns (cf. John \& Srivastava, 1999). The chronic negative affective state of the neurotic may itself act as a mental load, soaking up some of the mental resources necessary to maintain mental control (cf. Dalgleish et al., 2009).

Despite this, under normative conditions - that is with no additional load of anxiety - we argue that the neurotic individual will have sufficient cognitive space for the operating process to work effectively. However, under anxiety-provoking conditions - in which the neurotic individual's experience of distressing emotions is increased and less cognitive space remains for the operating process to operate effectively - the neurotic individual's monitoring process will become salient and ironically bring into consciousness the specifically to-beavoided state. In contrast, the cognitive resources of the emotionally stable (i.e., low neurotic) individual are not consumed by generalized concerns and worries. Thus, in line with Wegner's postulate, we argue that even under conditions of high-anxiety, emotionally stable individuals will have the requisite cognitive resources to maintain the salience of the operating process. In this way, for emotionally stable individuals, the specifically to-beavoided state will not be brought into consciousness.

Despite such a strong theoretical basis for examining potential personality moderators of ironic performance errors, only Woodman and Davis (2008) have to date taken up this mantle. Woodman and Davis (2008) explored individual anxiety coping styles as a moderator of ironic performance errors. They revealed that repressors were significantly more prone to suffer from ironic performance errors when compared to both low- and high-anxious non- 
1 repressors. In line with the present theoretical rationale, Woodman and Davis (2008)

2 concluded that the additional mental load that repressors experience by denying their anxiety

3 undermines the operating process. The Woodman and Davis (2008) investigation provides

4 promising initial evidence that the extent to which individuals invest (mental) effort in self-

5 and emotion-regulation moderates their susceptibility to producing ironic performance errors

6 when anxious. However, the Woodman and Davis (2008) investigation was limited by its

7 lack of differentiation between ironic and non-ironic performance error (Woodman et al.,

8 2015). Indeed, Woodman et al. (2015) noted that there are two main shortcomings of the

9 previous limited research on ironic performance error: (1) the failure to differentiate ironic

10 and non-ironic error; and (2) a reliance on working memory tasks (as opposed to anxiety) to

11 increase cognitive load. Consequently, in the present studies we clearly differentiate ironic and non-ironic performance error and we induce mental load by manipulating anxiety via an ecologically valid performance stressor. Specifically, we aim to manipulate anxiety using a performance-contingent financial reward (i.e., the opportunity to gain a financial reward as recompense for performance accomplishments), a method which has been successfully implemented in previous research (e.g., Bell \& Hardy, 2009; Woodman \& Davis, 2008; Woodman et al., 2015; Wright, Killebrew, \& Pimpalapure, 2002). Furthermore, and of primary importance, we provide the first examination of neuroticism as a moderator of both the occurrence (Study 1 and Study 2) and precision (Study 2) of ironic error within a 20 performance domain.

\section{Study 1}

In the present study we aimed to extend Wegner's theory by providing the first test of neuroticism as a moderator of ironic performance error. Bakker, Oudejans, Binsch and Van der Kamp (2006) and Binsch, Oudejans, Bakker, Hoozemans and Savelsbergh (2010) successfully used a football penalty shooting task - which given their experimental design 
1 was by necessity laboratory based - to examine the influence of final target fixation on ironic

2 performance error. In the present study, with the aim of increasing ecological validity, we

3 employed a football penalty shooting task that has three major differences to the penalty

4 shooting task employed in the Bakker et al. (2006) and Binsch et al. (2010) studies.

5 Specifically, we used a regulation size 5 FIFA approved football (as opposed to a size 4 foam

6 ball), a standard football goal located outside (as opposed to a screen with a projected image

7 of a football goal located in a laboratory), and a standard $11 \mathrm{~m}$ penalty kick (as opposed to

8 penalty kicks from $2.48 \mathrm{~m}$ and $2.83 \mathrm{~m}$, respectively). In line with Wegner's theory, we

9 hypothesized that neurotics would demonstrate significantly greater increases in ironic

10 performance error, and decreases in target hits, from low-anxiety to high-anxiety conditions

11 than their comparatively emotionally stable counterparts. Importantly, in terms of providing specific support for the theory of ironic processes, neuroticism should not moderate significantly the incidence of non-ironic error across anxiety conditions.

\section{Method}

Participants. Before a university team-training session, we approached experienced male football players and invited them to participate in the study. The inclusion criteria were that participants represent one of the top three squads at the university and trained and/or played in a match at least once per week throughout the competitive season. The final sample comprised 67 male university football players $\left(M_{\text {age }}=20.55, S D=1.92\right)$.

\section{Measures}

Anxiety. We measured anxiety using the Mental Readiness Form-3 (MRF-3; Krane, 1994). The MRF-3, which comprises three single-item factors, requires participants to express how they feel right now by placing a mark on three separate $10 \mathrm{~cm}$ visual-analog scales. From left to right the scales are anchored: worried - not worried (cognitive anxiety); tense - not tense (somatic anxiety); and confident - not confident (self-confidence). Thus, 
1 high scores represent low cognitive anxiety, low somatic anxiety and low self-confidence.

2 We preferred the MRF-3 to the Competitive State Anxiety Inventory-2 (CSAI-2; Martens,

3 Burton, Vealey, Bump, \& Smith, 1990) because it is more expedient and less intrusive to

4 administer. As such, we were able to deliver the experimental instructions and measure the

5 participant's anxiety in close temporal proximity. Additionally, given that the present

6 research revolves around the experience of anxiety, we preferred the use of the word

7 "worried" in the MRF-3 which better captures the experience of anxiety compared to the use

8 of the more ambiguous term "concern" in the CSAI-2 (see also Woodman \& Hardy, 2001).

9 The MRF-3 has been used in previous studies to assess anxiety in competitive settings (e.g.,

10 Robazza, Bortoli, \& Nougier, 2000; Woodman \& Davis, 2008) and is significantly correlated

11 with the CSAI-2 (Krane, 1994): .58 (cognitive anxiety), .59 (somatic anxiety), and .77 (selfconfidence).

Neuroticism. The 50-item International Personality Item Pool (IPIP; Goldberg, 1999) measures emotional stability, extraversion, openness to experience, agreeableness, and conscientiousness. We used the 10-item emotional stability factor (e.g., I get upset easily) as a measure of neuroticism on a five-point Likert scale $(1=$ very inaccurate $; 5=$ very accurate). High emotional stability scores reflect low neuroticism. This factor has been shown to have strong internal consistency ( $\alpha=.86$; Goldberg, 1999; Gow, Whiteman, Pattie, \& Deary, 2005).

Performance. We measured performance on a flat Astroturf surface using a regulation size 5 FIFA approved football, a standard football goal, and a standard $11 \mathrm{~m}$ penalty kick (FIFA, 2013). A target zone was delimited by a rope that hung vertically from the football crossbar to the ground, $1 \mathrm{~m}$ from the right-hand post. Both the ironic error zone (to the right of the target zone and delimited by a cone) and the non-ironic error zone (to the left of the target zone and delimited by a rope) were the same size as the target zone (i.e., 1 
1 meter wide and 2.44 meters high; see Figure 1). Left-footed participants were given a

2 mirrored set-up. Specifically, their target zone was marked one meter in from the left-hand

3 post with the ironic error zone to the left of the target zone and non-ironic error zone to the

4 right. We operationalized performance as the number of shots hit into each zone (ironic error

5 zone, target zone, non-ironic error zone), which was recorded by a qualified Level 1 Football

6 Association coach who stood directly behind the strike of the ball. The coach was male, aged

725 , and himself an experienced football player (University $1^{\text {st }}$ team). Shots that did not clearly

8 enter one of the three zones were retaken $(0.5 \%)$.

Procedure. We first obtained institutional ethics approval for the study. On arrival at

10 the test site, each participant reported their preferred kicking foot and completed the IPIP.

11 The experimenter reminded each participant that the football-shooting task would comprise taking two sets of 20 penalty kicks. The experimenter then described the scoring system for the penalty-shooting task. Instructions regarding the location of the target and error zones were specific to whether the participant was right- or left-footed. Right-footed participants were told that they would score 10 points for hitting the target zone, zero points for hitting the left of the target zone (non-ironic error zone) and minus five points for hitting the right of the target zone (ironic error zone). The verbal instructions concluded with the priming phrase, "Try to hit the target zone. Be particularly careful not to hit the ball to the right of the post, as you will score minus five points each time you do." We gave left-footed players mirrored instructions. Immediately before striking the first ball in the low-anxiety condition, we reminded participants of the instructional set and then completed the MRF-3 before we repeated the priming phrase to them. In the high-anxiety condition, we used the same procedure with one exception: Before completing the MRF-3, we informed participants of the performance-contingent financial reward. Specifically, we told participants that we would award $£ 100$ (approx. US\$155) to the participant with the highest performance score. In both 
1 conditions, participants took 20 penalty kicks. We counter-balanced the order of presentation

2 for the anxiety conditions across participants and we gave all participants a two-minute break

3 between conditions.

Analysis. We used Judd, Kenny, and McClelland's (2001) regression procedure to test within-subjects moderation. Specifically, we examined the potential moderating effects

6 of neuroticism $(N)$ on performance - performance was operationalized as the total number of

7 shots hit into the (1) ironic error zone, (2) target zone and (3) non-ironic error zone - in a

8 repeated measures (high-anxiety and low-anxiety) design. The advantage of employing the

9 Judd et al. (2001) approach in the present studies is that this method is not bound by the

10 large-sample assumptions underlying certain estimation procedures in multilevel modelling.

11 Based on the Judd et al. (2001) methodology we first regressed low-anxiety performance $\left(\hat{Y}_{1}\right)$ and high-anxiety performance $\left(\hat{Y}_{2}\right)$ on neuroticism (see Table 1$)$. To examine neuroticism as a moderator we regressed the performance difference $-Y_{\mathrm{d}}$ (i.e., $Y_{1}-Y_{2}$ ) - on neuroticism. The test of whether this slope differs from zero is equivalent to testing whether the slope for neuroticism in the high-anxiety condition (i.e., the $Y_{2}$ equation) differs from the slope for neuroticism in the low-anxiety condition (i.e., the $Y_{1}$ equation). A significant neuroticism $\times$ performance interaction is evidence of a significant moderation effect (see Judd et al., 2001).

Results

Anxiety manipulation. Paired samples $t$-tests on the MRF-3 data confirmed that the anxiety manipulation was successful. Specifically, participants' cognitive anxiety was higher

21 in the high-anxiety condition $(M=7.30, S D=2.19)$ compared to the low-anxiety condition $(M=9.07, S D=1.82 ; t(66)=6.73, p<.001)$. Somatic anxiety was higher in the high-anxiety condition $(M=7.33, S D=2.17)$ compared to low-anxiety condition $(M=8.69$, $S D=2.05 ; t(66)=4.70, p<.001)$. Self-confidence was significantly lower in the high- 
1 anxiety condition $(M=5.25, S D=2.49)$ compared to low-anxiety condition $(M=4.16, S D=$ $2.09 ; t(66)=5.26, p<.001)$.

Performance. The results provide support for the hypothesis that neuroticism moderates the incidence of both ironic performance error and target hits across anxiety conditions. Importantly, non-ironic error was unaffected (see Table 1 and Figure 2).

6 Specifically, neurotics demonstrated significantly greater increases in ironic performance

7 error, and decreases in target hits, from low-anxiety to high-anxiety conditions than their comparatively emotionally stable counterparts.

\section{Discussion}

Study 1 provides the first evidence that neuroticism moderates the incidence of anxiety-induced ironic performance errors. As hypothesized, neurotics experienced greater increases in ironic performance error and greater decreases in target hits, from low-anxiety to high-anxiety conditions, than their comparatively emotionally stable counterparts.

Importantly, neuroticism did not moderate the incidence of non-ironic error. That is, it was specifically neurotics' incidence of ironic error rather than their generic error that was affected by anxiety.

Using a 'real-world' penalty shooting task is an improvement in ecological validity compared to previous laboratory-based penalty-shooting tasks (e.g., Bakker, et al., 2006; Binsch et al., 2010). However, the ecological validity of the task was limited in that the nonironic error zone was operationalized within the goal itself (see Figure 1). Thus, although we classified shots entering the non-ironic error zone as an 'error' (i.e., failure to hit the target zone), shots that entered this zone in a 'real-world' football penalty could go past the goalkeeper into the goal. A more serious limitation is that the fixed location of the non-ironic error zone could have introduced a systematic performance bias. Specifically, for right-footed participants, the non-ironic error zone was consistently located to the left of the target zone, 
1 and the ironic error zone was consistently located wide of the goal to the right (we used a

2 mirrored set-up for left-footed participants). Thus, despite no theoretical or empirical

3 evidence for the postulate that anxious footballers might systematically 'slice' penalty kicks

4 to the outside of the goal (reflective of systematized error rather than ironic performance error

5 per se), such a postulate cannot be dismissed. We address this limitation in Study 2.

6

\section{Study 2}

The reader will recall Bill, the PGA tour golfer who is also a worrier. Bill hit his golf ball into the lake when playing his tee shot at the final hole. He did the very thing he was specifically trying to avoid doing. But Bill's tee shot was not just a marginal error (i.e., the golf ball didn't only just miss the fairway and roll slowly into the very edge of the lake). Rather, Bill hooked his tee shot high, wide, and into the very middle of the lake. Bill's shot was precisely ironic. In a performance setting, such precision is laudable and sought after, if only it were not specifically counter-intentional. However, researchers have typically dichotomized the incidence of ironic errors rather than investigating the specific precision of any ironic errors.

The aim of Study 2 was threefold: First, we aimed to replicate the moderating role of neuroticism on the incidence of ironic performance error, as revealed in Study 1, using a different task. The hypothesis remained unchanged. That is, neurotics will demonstrate significantly greater increases in ironic performance error, and decreases in target hits, from low-anxiety to high-anxiety conditions than their comparatively emotionally stable counterparts. Again, we hypothesized that non-ironic error would not significantly change across anxiety conditions.

Second, we aimed to examine the precision of irony in ironic performance errors (see Woodman et al., 2015) as moderated by neuroticism. That is, we aimed to examine whether neurotic individuals' ironic errors are more precisely ironic when anxious compared to 
1 emotionally stable individuals' errors. As argued previously, maintaining emotion regulation

2 in daily-life consumes more of the neurotic individuals' cognitive resources compared to their

3 emotionally stable counterparts. Thus, for the neurotic individual, conditions of elevated

4 mental load - such as high-anxiety - occupy the critical mental capacity required to maintain

5 the salience of the operating process. Since a salient monitoring process increases an

6 individual's conscious awareness of the specifically to-be-avoided state, we argue that under

7 conditions of high-anxiety neurotics will more precisely do the very thing they are trying not

8 to do. Thus, we hypothesize that under conditions of high-anxiety neurotics' ironic error zone

9 hits will be farther away from the target zone and more precisely within the ironic error zone

10 compared to emotionally stable individuals.

11 Third, we introduced three methodological modifications to improve the methodology used in Study 1: (a) We included an additional stressor - social evaluation - to enhance the ecological validity of inducing mental load in a competitive sporting environment. Previous research has utilized social evaluation to successfully manipulate anxiety (Bell \& Hardy, 2009; Hardy et al., 1996; Woodman et al., 2015; Woodman, Roberts, Hardy, Callow \& Rogers, 2011); (b) We included an indicator of participants' physiological arousal with the aim of deriving a more reliable measure of anxiety change across conditions; (c) To dismiss the postulate that Study 1 results can be attributed to systematic performance bias (as a consequence of the ironic error zone being in a consistent direction relative to the target), we

20 varied the location of the ironic error zone across participants.

\section{Method}

Participants. We used poster adverts to recruit 73 participants (45 men, 28 women; times.

\section{Measures.}


Anxiety. We administered the MRF-3 (Krane, 1994), as described in Study 1, to measure cognitive anxiety, somatic anxiety and self-confidence. Additionally, we measured physiological arousal by recording heart rate (HR) and heart rate variability (HRV) using the Polar RS800CX heart rate monitor (Quintana, Heathers \& Kemp, 2012). We analyzed individuals' HR and HRV data from the final three minutes of their engagement in both the high-anxiety and low-anxiety conditions. Researchers have previously used HR and HRV as a successful indicator of participants' physiological response to anxiety (e.g., Cervantes, Rodas, \& Capdevila, 2009; Laborde, Brull, Weber, \& Anders, 2011; Mateo, Lafarga, Navarro, Guzman \& Zabala, 2012; Murray \& Raedeke, 2008).

Neuroticism. The 10-item Big Five Inventory-10 (BFI-10; Rammstedt \& John, 2007) measures extraversion, agreeableness, conscientiousness, neuroticism, and openness on a five-point Likert scale $(1=$ strongly disagree $; 5=$ strongly agree $)$. We used the neuroticism factor, which comprises two items: I see myself as someone who is relaxed, handless stress well (reverse-scored item); I see myself as someone who gets nervous easily. This factor has been shown to have strong internal consistency $(\alpha=.88$; Denissen, Geenen, Selfhout, $\&$ van Aken, 2008) and Rammstedt \& John (2007) revealed it has both good test-retest reliability (.75) and correlates well with the eight-item BFI-44 (John \& Srivastava, 1999) neuroticism factor (.86).

Performance. We measured dart-throwing performance using a regulation dartboard and darts. We positioned the center of the dartboard $1.73 \mathrm{~cm}$ from the floor and $2.37 \mathrm{~m}$ horizontally from the Oche (throwing line). Following removal of the standard wireframe, we placed a paper coversheet that matched the dimensions of the dartboard over the dartboard (see Figure 3). On the dartboard cover sheet we marked in black a central circle - the target zone - which measured $6 \mathrm{~cm}$ in diameter. Participants scored nine points for hitting the target zone. Darts landing in the next concentric circle scored eight points. Darts landing in the next 
1 concentric circle scored seven points. The scoring system continued in the same manner to

2 the outermost concentric circle, which scored one point. All concentric circles were $2.1 \mathrm{~cm}$

3 wide, except the outermost one, which was $3.9 \mathrm{~cm}$ wide to accommodate the cover sheet to

4 the edge of the dartboard.

A single quadrant (e.g., top-right quadrant of the dartboard excluding the area of the target zone that fell within the quadrant) was operationalized as the ironic error zone. We informed participants that they would score zero points for any darts landing within this zone. We designated the ironic error zone as the top-right quadrant for the first participant. We then rotated clockwise the location of the ironic error zone by one quadrant for each subsequent participant. Thus, for the second participant the ironic error zone was the bottom right quadrant. Each time, we conceptualized the quadrant opposite the ironic error zone as the non-ironic error zone but we did not mention this to the participants. Hits in the non-ironic error zone scored between one and eight points dependent on the proximity to the target zone. An observer recorded the zone hit for each dart. Darts that missed the dart board entirely were retaken $(0.3 \%)$.

Procedure. Using a standardized instructional set, the experimenter informed each participant that the task - as approved by the university ethics committee - would comprise two sets of 24 dart throws and described the scoring system for the dart-throwing task.

Participants completed an informed consent form with additional demographic data (age, sex, and experience) and wore a heart rate chest strap transmitter. Before the task, we conducted a warm up that consisted of 15 practice throws, the scores of which were not recorded. These 15 shots primarily served as a warm-up rather than as a meaningful task familiarization; that is, despite all participants being inexperienced darts players, we did not consider the task to be a difficult one with which to familiarize oneself. 
Our pilot testing revealed that (similarly inexperienced) participants who initially performed in the high-anxiety condition often remained highly anxious, even after a twominute break, when subsequently participating under conditions of supposed low-anxiety. As such, to minimize any anxiety carryover effect, we fixed the order of the presentation of anxiety conditions for all participants as low-anxiety first and high-anxiety second (cf. Hardy \& Hutchinson, 2007). Thus, the task required each participant to perform 24 throws in the low-anxiety condition, followed by a two-minute break, and 24 throws in the high-anxiety condition. Each participant completed the dart-throwing task individually.

Immediately before the first dart throw, in the low-anxiety condition, we repeated the instructional set to the participants who then completed the MRF-3. These verbal instructions concluded with the priming phrase, "Please try to hit the target zone, or as close to the target zone as possible, in order to gain maximal points, but be particularly careful not to hit the top right quarter ${ }^{1}$ of the dart board, as you will score zero points each time you do so." We used the same procedure in the high-anxiety condition with one exception: Before completing the MRF-3, we informed participants that, for one week, we would display all scores publically on a television screen located in a busy indoor thoroughfare of the university. Additionally, we informed each participant that the highest scoring participant would receive $£ 50$ (approx. US\$80).

\section{Results}

Anxiety manipulation. Both physiological arousal and self-report anxiety measures confirmed the anxiety manipulation. Specifically, paired samples $t$-tests on the MRF-3 data revealed that participants' cognitive anxiety was higher in the high-anxiety condition $(M=$ $6.37, S D=2.86)$ compared to the low-anxiety condition $(M=8.10, S D=2.48 ; t(72)=6.03, p$

${ }^{1}$ The priming phrase was modified to reflect the changing position of the ironic error zone between participants: (a) bottom right quarter (b) bottom left quarter (c) top left quarter. 
$1<.001)$. Somatic anxiety was higher in the high-anxiety condition $(M=6.09, S D=2.57)$

2 compared to low-anxiety condition $(M=7.63, S D=2.60 ; t(72)=4.93, p<.001)$. Self-

3 confidence was significantly lower in the high-anxiety condition $(M=6.17, S D=2.22)$

4 compared to low-anxiety condition $(M=5.46, S D=2.06 ; t(72)=2.94, p=.004)$.

5 Additionally, participants' HR was significantly higher in the high-anxiety condition $(M=$

$696.03, S D=14.20)$ compared to low-anxiety condition $(M=85.83, S D=12.72 ; t(72)=9.42$,

$7 \quad p<.001$ ). We examined HRV using both standard deviation of R wave intervals (SDNN) and

8 root mean square of successive R-R intervals (r-MSSD), where low values (i.e., low HRV)

9 represent a high stress response. Specifically, SDNN was significantly lower in the high-

10 anxiety condition $(M=64.34, S D=17.69)$ compared to the low-anxiety condition $(M=$

$1175.34, S D=18.93 ; t(72)=6.23, p<.001)$ and $r-M S S D$ was significantly lower in the high anxiety condition $(M=35.05, S D=15.27)$ compared to the low-anxiety condition $(M=$ 40.63, $S D=15.48 ; t(72)=4.37, p<.001)$.

Performance. As in Study 1, we applied the Judd et al. (2001) within-subjects regression procedure to examine the potential moderating effect of neuroticism on performance. Results again provide support for the hypothesis that neuroticism moderates significantly the incidence of both ironic performance error and target hits - but not nonironic error - across anxiety conditions (see Table 1 and Figure 2). Specifically, as in Study 1, neurotics demonstrated significantly greater increases in ironic performance error, and decreases in target hits, from low-anxiety to high-anxiety conditions than their comparatively emotionally stable counterparts.

How precisely ironic are ironic errors? Woodman et al. (2015) conceptualized the precision of irony, for ironic error zone hits, via two measures of irony. We adopted their approach to test the hypothesis that neurotic participants would perform in a more precisely ironic fashion when anxious compared to their emotionally stable counterparts. Specifically, 
1 we took each participant's mean radial error within the ironic zone as the measure of the

2 distance from the target zone. Second, we took each participant's mean arc-length within the

3 ironic zone (from the closest non-ironic zone) as the measure of the distance into the ironic

4 zone (see Figure 4). Results provide support for the hypothesis that across anxiety conditions

5 neuroticism moderates significantly how precisely ironic participants' ironic performance

6 errors are (see Table 1). Specifically, neurotics demonstrated significantly greater increases in

7 both mean arc-length and mean radial error (of their ironic error zone hits) from low-anxiety

8 to high-anxiety conditions than their comparatively emotionally stable counterparts ${ }^{2}$.

\section{Discussion}

Results support the Study 1 findings that neuroticism moderates significantly the

11 incidence of ironic performance error when anxious. This replication is important since, unlike in Study 1, in the present study we varied the location of the ironic and non-ironic error zones across participants. As such, we demonstrated that the results cannot be attributed to generalized performance breakdown under conditions of high-anxiety, but rather represent a precisely ironic performance decline.

\footnotetext{
${ }^{2}$ We have focused on the incidence of ironic effects across both studies and have revealed a greater incidence of ironic error (and not of generic, non-ironic, error) from low- to high-anxiety for individuals higher in neuroticism. When testing for anxiety-induced ironic effects, other researchers (e.g., de la Peña et al., 2008) have revealed overcompensation effects (albeit not investigating neuroticism as a moderator). As such, to explore the potential incidence of overcompensation, we ran paired samples $t$-tests examining changes in nonironic error from low-anxiety to high-anxiety conditions. In Study 1, there was no significant increase in the incidence of non-ironic error from low-anxiety $(M=4.72, S D=2.27)$ to high-anxiety $(M=4.51, S D=2.32)$ conditions, $t(66)=.84, p=.40$. Similarly, in Study 2, there was no significant increase in the incidence of nonironic error from low-anxiety $(M=7.30, S D=2.93)$ to high-anxiety $(M=7.58, S D=2.55)$ conditions, $t(72)=$ $.98, p=.33$.
} 
Additionally, Study 2 provides the first evidence that, under conditions of highanxiety, neuroticism moderates the precision of irony in ironic performance errors.

Specifically, as hypothesized, from low-anxiety to high-anxiety conditions, there was a significantly greater increase in neurotics' ironic error zone hits as reflected by mean arclength and mean radial error - compared to their comparatively emotionally stable counterparts.

\section{General Discussion}

We provide the first evidence for the moderating role of personality in both the incidence and precision of irony of ironic performance errors under conditions of highanxiety. Across two studies, neurotic individuals experienced significantly greater increases in ironic performance error and greater decreases in target hits, from low-anxiety to highanxiety conditions. Their comparatively emotionally stable counterparts suffered no such ironic performance decrements. Importantly, in terms of providing specific support for Wegner's theory of ironic processes, neuroticism did not moderate significantly the incidence of non-ironic error. Additionally, Study 2 results provide the first evidence that under conditions of high-anxiety, neuroticism moderates the precision of irony in ironic performance errors. Specifically, as hypothesized, from low-anxiety to high-anxiety conditions, there was a significantly greater increase in neurotics' ironic error zone hits as reflected by both the distance from the closest non-ironic error zone (arc-length) and the distance from the target zone (radial error). Previous research examining ironic effects of performance has utilized performance tasks and performance stressors with limited ecological validity (e.g., Bakker et al., 2006; Binsch et al., 2010; Oudejans, et al., 2013). We addressed this limitation by employing ecologically valid performance tasks (e.g., Non-laboratory based penalty shooting) and ecologically valid performance stressors (e.g., Performance-contingent financial reward and social evaluation). 
The neurotic individual's life is characterized by the experience of more frequent distressing emotions, and more elevated negative reactions to such emotions, compared to their emotionally stable (low neurotic) counterparts (Bolger \& Zuckerman, 1995). As such, self- and emotion-regulation processes demand more cognitive resources for the neurotic individual when compared to the emotionally stable individual even under normative conditions of supposed low-anxiety (Gross, 2007). Consuming critical cognitive space with more general self- and emotional-regulation processes leaves the neurotic individual susceptible to overwhelming their cognitive capacity when additional processes - such as dealing with high-anxiety situations - tax their working memory. The present results support the theoretical position that, for neurotic individuals, the additional cognitive load of engaging in a high-anxiety sport-performance task is enough to tax cognitive resources to the degree that the operating process cannot work effectively. Consequently, the monitoring process becomes salient, which increases the likelihood of experiencing a precisely ironic performance breakdown under pressure (Wegner, 2009).

Interestingly, emotional stability was associated with fewer ironic errors and a greater number of target hits under conditions of high-anxiety compared to low-anxiety. In the context of ironic processes theory, in the low-anxiety condition - in lieu of either a perceived incentive and/or a significant stressor - emotionally stable individuals may have processed both relevant and irrelevant attentional cues (Eysenck et al., 2007; Weinberg \& Gould, 2007) as a consequence of boredom (Brissett \& Snow, 1993) or under-arousal (Hardy, 1990).

Emotional stability is a strong predictor of positive interpretations of anxiety (e.g., challenge, excitement) and positive emotion (DeNeve \& Cooper, 1998; Hills \& Argyle, 2001). As such, emotionally stable individuals may use the stressor and/or the reward as a motivational tool to concentrate their attentional focus primarily on salient aspects of the performance task (Jones, Swain, \& Hardy, 1993). In doing so, the emotionally stable performer is able to increase 
1 effort and free-up any cognitive resources that had been consumed processing irrelevant cues

2 (Eysenck et al., 2007). In other words, conditions of high-anxiety may afford the emotionally stable individual more cognitive resource, and thus increase the likelihood of the (operating and monitoring) control system working effectively.

The present results support the postulate that anxiety exerts differential effects on individuals' susceptibility to producing ironic performance errors (cf. Diener, Larsen, \& Emmons, 1984; Woodman \& Davis, 2008). The influence of personality and individual differences on the precise nature of performance breakdown when anxious has considerable applied implications for practitioners. For example, given that neuroticism can be reliably assessed via a two-item measure (Rammstedt \& John, 2007) it is feasible to assess an athlete's neuroticism and (1) for coaches to individualize their own coaching behaviors accordingly or (2) for sporting systems to align athletes with a coach whose behaviors will most complement their neuroticism. For example, research suggests that during competitive scenarios cognitive load is increased for those athletes who perceive that their coach exhibits negative activation coaching behaviors; that is low emotional composure that increases the athlete's feelings of tension and worry (Williams et al., 2003). As argued previously, elevated cognitive load increases the likelihood of a (neurotic) individual's monitoring process becoming salient relative to their operating process, thus increasing the incidence of ironic performance errors. Furthermore, negative activation coaching behaviors increases athletes' negative self-talk (Zourbanos, Theodorakis \& Hatzigeorgiadis, 2006). To continue with the golfing example from earlier, negative self-talk may comprise self-statements such as, 'Don't mess up here by hooking the golf ball into the lake". In a competitive environment - that is, under conditions of relatively high-anxiety when the monitoring process is salient over the operating process - the neurotic athlete's internalized negative self-talk could ironically bring into consciousness the specifically to-be-avoided state (i.e., hitting the golf ball into the lake). 
1 It is worth noting that negative activation coaching behaviors may not prove acutely

2 detrimental to the neurotic individual's performance under conditions of low-anxiety (i.e.,

3 during training). In other words, the athlete's increased cognitive load and increased negative

4 self-talk that is associated with experiencing perceived negative activation coaching

5 behaviors would not increase ironic performance errors if the neurotic individual has the

6 cognitive capacity to accommodate such additional mental load (i.e., in a training

7 environment). As such, a coach may not overtly witness any (ironic) performance breakdown

8 that is directly caused by their negative activation coaching behaviors because the low-

9 anxiety (training) environment does not directly result in ironic performance breakdown.

10 Indeed, it is only when the individual transfers his/her negative activation to the high-anxiety

11 environment (e.g., competition) that the likelihood of the ironic performance breakdown

12 dramatically increases. This issue is further compounded by the majority of a coach's time

13 being spent with an athlete when the athlete is not in anxiety-inducing environment. As such,

14 the coach might understandably argue that his/her coaching techniques and feedback are

15 effective. However, although the coach who employs negative activation behaviors with the

16 neurotic athlete may produce exceptional performances in training (i.e., low-anxiety

17 condition), they may fail to repeat such elevated performances in the 'heat of competition'

18 (i.e., high-anxiety condition). Research would do well to examine the extent to which

19 coaching behaviors such as emotional composure and esteem support provide a buffer from

20 the effects of anxiety on ironic performance errors for neurotic individuals (see also Kenow

$21 \&$ Williams, 1992).

Future research should examine the precise mechanisms that may underpin the

23 neurotic's susceptibility to ironic performance error when anxious. Indeed, personality

24 variables beyond the Big Five have considerable potential in moderating the incidence of

25 ironic performance error and are worthy of research attention. Alexithymia is one such 
1 personality trait that has been subject to little research attention in the competitive sport

2 domain (Roberts \& Woodman, 2015). Alexithymia is the difficulty in identifying emotions

3 and an inability to express them (Taylor, Bagby \& Parker, 1997). The alexithymic

4 individual's difficulty in interpreting emotional signals frequently impedes their interpersonal

5 relationships (Taylor et al., 1997). However, beyond the high-risk sport domain (e.g.,

6 Woodman, Hardy, Barlow \& Le Scanff, 2010), research to date has failed to consider any

7 functional aspects of alexithymia (Roberts \& Woodman, 2015). The alexithmic individual's

8 somewhat 'blunted' emotional response may prove advantageous in the competitive sporting

9 domain. Specifically, alexithymic individuals may not acknowledge the distinct and profuse

10 intense emotions that are typically concomitant with the (high-anxiety) competitive

11 performance environment: the very emotions that for most individuals - and neurotics in

12 particular - increase cognitive load and the associated tax on cognitive resources.

In the present research we did not primarily aim to test directly de la Peña et al.'s

(2008) implicit overcompensation hypothesis. However, in line with recommendations by

Woodman et al. (2015), we clearly differentiated ironic and non-ironic performance error.

The precise nature of this differentiation made possible an examination of overcompensation.

Specifically, the non-ironic error zone was located on the opposite side of the target zone to the ironic error zone. Thus, evidence that participants hit more penalty kicks (Study 1) or threw more darts (Study 2) in the non-ironic error zone under conditions of high-anxiety (compared to low anxiety) would be evidence of overcompensation. No such difference was evident in either Study 1 or Study 2. Although there was no difference in non-ironic error between low- and high-anxiety conditions, the incidence of non-ironic error was consistently higher than the incidence of ironic error, regardless of anxiety condition, in both Study 1 and Study 2. In other words, although an individual is more likely to commit an ironic error when anxious (compared to when not anxious) an individual is also more likely to commit a non- 
1 ironic error (compared to an ironic error) regardless of whether that individual is anxious or not.

In the present research a single observer adjudged whether penalty kicks (Study 1) or dart throws (Study 2) had entered one of the three zones (ironic error, non-ironic error, or target zones). He asked participants to retake the shot if the shot had missed all three zones. As such, we cannot dismiss the postulate that shots or darts not entering one of the three designated zones were evidence of 'extreme' ironic or compensatory non-ironic errors. This approach is a limitation that is mitigated only by the fact that $\leq 0.5 \%$ of shots/darts were unclassified (and were thus retaken). Nonetheless, given that 'wild' shots could reflect extreme cases of irony when least desired, research that is geared specifically to explore such incidences, rather than to dismiss them, would clearly advance our understanding of ironic processes of performance. Researchers would do well to grapple with specifically how one might conduct such an experiment. The single-source methodology is also a limitation of the present studies. First, by verbally informing each participant of the stressor (i.e., the financial reward and the social evaluation), the observer was not blind to the respective anxiety condition (high- or low-anxiety). Importantly, however, the observer was blind to the participants' neuroticism scores. As such, even if one were to argue that the experimenter biased the results, such experimenter bias could not account for the observed three-way interaction. This robust interaction meaningfully mitigates any such concern.

The primary limitation of Study 1 was that the location of the ironic error zone remained consistent. Thus, we could not dismiss systematic performance bias as a potential explanation of the findings. In Study 2, we were able to dismiss this alternate explanation of the results by varying the location of both the ironic and non-ironic error zones across participants (see also Woodman et al., 2015). Additionally, one can be confident in the generalizability of the present findings because of the methodological differences between 
1 Study 1 and Study 2, namely the performance tasks (football, darts) and the experience of

2 participants (expert and novice). In summary, the data across two studies provide new and

3 compelling evidence that neuroticism moderates both the incidence and the precision of irony

4 of ironic performance error when anxious. 


\section{References}

2 Bandura, A. (1977). Self-efficacy: Towards a unifying theory of behavior change. Psychological Review, 84, 191-214. doi: 10.1037/0033-295X.84.2.191

Baumeister, R. F. (1984). Choking under pressure: Self-consciousness and paradoxical effects of incentives on skillful performance. Journal of Personality and Social Psychology, 46, 610-620. doi: 10.1037/0022-3514.46.3.610

Bakker, F. C., Oudejans, R. R. D., Binsch, O., \& Van der Kamp, J. (2006). Penalty shooting and gaze behavior: Unwanted effects of the wish not to miss. International Journal of Sports Psychology, 37, 265 -280.

Bell, J. J., \& Hardy, J. (2009). Effects of attentional focus on skilled performance in golf. Journal of Applied Sport Psychology, 21, 163-177. doi: 10.1080/10413200902795323

Binsch, O., Oudejans, R. R. D., Bakker, F. C., Hoozemans, M. J. M., \& Savelsbergh, G. J. P. (2010). Ironic effects in a simulated penalty shooting task: Is the negative wording in the instruction essential? International Journal of Sport Psychology, 41, 118-133.

Binsch, O., Oudejans, R. R. D., Bakker, F. C., \& Savelsbergh, G. J. P. (2009). Unwanted effects in aiming actions: The relation between gaze behavior and performance in a golf putting task. Psychology of Sport and Exercise, 10, 628-635. doi: 10.1016/j.psychsport.2009.05.005

Bolger, N., \& Schilling, E. A. (1991). Personality and the problems of everyday life: The role of neuroticism in exposure and reactivity to daily stressors. Journal of Personality, 9, 355-386. doi: 10.1111/j.1467-6494.1991.tb00253.x

Bolger, N., \& Zuckerman, A. (1995). A framework for studying personality in the stress process. Journal of Personality \& Social Psychology, 69, 890-902. doi: $10.1037 / 0022-3514.69 .5 .890$ 
1 Brissett, D., \& Snow, R. P. (1993). Boredom: Where the future isn't. Symbolic Interaction, 16, 237-256. doi: 10.1525/si.1993.16.3.237

3 Cervantes, B., Rodas, F. G., \& Capdevila, O. L. (2009). Heart-rate variability and precompetitive anxiety in swimmers. Psicothema, 21, 531-536.

Costa, P. T., \& McCrae, R. R. (1987). Neuroticism, somatic complaints, and disease: Is the bark worse than the bite? Journal of Personality, 55, 299-316. doi: 10.1111/j.14676494.1987.tb00438.x

Davis, C., \& Mogk, J. P. (1994). Some personality correlates of interest and excellence in sport. International Journal of Sport Psychology, 25, 131-143.

Dalgleish, T., Yiend, J., Schweizer, S., \& Dunn, B. D. (2009). Ironic effects of emotion suppression when recounting distressing memories. Emotion, 9, 744-749. doi: 10.1037/a0017290

de la Peña, D., Murray, N. P., \& Janelle, C. M. (2008). Implicit overcompensation: the influence of negative self-instructions on performance of a self-paced motor task. Journal of Sport Sciences, 26, 1323-1331. doi: 10.1080/02640410802155138

DeNeve, K. M., \& Cooper, H. (1998). The happy personality: A meta-analysis of 137 personality traits and subjective well-being. Psychological Bulletin, 124, 197- 229.

Denissen, J. J. A., Geenen, R., Selfhout, M., \& van Aken, M. A. G. (2008). Single-item big five ratings in a social network design. European Journal of Personality, 22, 37-54. doi: 10.1002/per.662

Diener, E., Larsen, R. J., \& Emmons, R. A. (1984). Person x situation interactions: Choice of situations and congruence response models. Journal of Personality and Social Psychology, 47, 580-590. 
1 Dugdale, J. R., \& Eklund, R. C. (2002). Do not pay any attention to the umpires: Thought suppression and task-relevant focusing strategies. Journal of Sport and Exercise Psychology, 24, 306-319.

Dugdale, J. R., \& Eklund, R. C. (2003). Ironic processing and static balance performance in high-expertise performers. Research Quarterly for Exercise \& Sport, 74, 348-352. doi: 10.1080/02701367.2003.10609102.

Eysenck, H. J., \& Eysenck, M. W. (1985). Personality and individual differences: A natural science approach. New York: Plenum Press.

Eysenck, M. W., Derakshan, N., Santos, R., \& Calvo, M. G. (2007). Anxiety and cognitive performance: Attentional control theory. Emotion, 7, 336-353. doi: 10.1037/15283542.7.2.336.

FIFA (2009, December 3). FIFA Laws of the Game. Retrieved from http://www.fifa.com/mm/document/affederation/federation/81/42/36/lawsofthegamee n.pdf

Goldberg, L. R. (1999). A broad-bandwidth, public domain, personality inventory measuring the lower-level facets of several five-factor models. In I. Mervielde, I. Deary, F. De Fruyt, \& F. Ostendorf (Eds.), Personality psychology in Europe (Vol. 7, pp. 7-28).

Gow, A. J., Whiteman, M. C., Pattie, A., \& Deary, I. J. (2005). Goldberg's IPIP Big-Five factor markers: Internal consistency and concurrent validation in Scotland. Personality and Individual Differences, 39, 317-329. doi: 10.1016/j.paid.2005.01.011.

22 Gross, J. (Ed.). (2007). Handbook of emotion regulation. New York: Guilford Press. 
1 Hall, C. R., Hardy, J., \& Gammage, K. L. (1999). About hitting golf balls in the water: Comments on Janelle's 1999 article on ironic processes. The Sport Psychologist, 13, 221-224.

Hardy, L. (1990). A catastrophe model of performance in sport. In J. G. Jones \& L. Hardy (Eds.), Stress and performance in sport (pp. 81-106). Chichester, UK: John Wiley \& Sons.

Hardy, L., \& Hutchinson, A. (2007). Effects of performance anxiety on effort and performance in rock climbing: A test of processing efficiency theory. Anxiety, Stress, and Coping, 20, 147-161. doi: 10.1080/10615800701217035.

Hardy, L., Mullen, R., \& Jones, G. (1996). Conscious control of motor actions under stress. British Journal of Psychology, 87, 621-636. doi: 10.1111/j.20448295.1996.tb02612.x.

Hills, P., \& Argyle, M. (2001). Emotional stability as a major dimension of happiness. Personality and Individual Differences, 31, 1357-1364. doi: 10.1016/S01918869(00)00229-4.

Hubbard, E. (1927). The notebook of Elbert Hubbard: Mottos, epigrams, short essays, passages, orphic sayings and preachments. New York: Wm. H. Wise \& Co.

Janelle, C. M. (1999). Ironic processes in sport: Implications for the sport psychologist. The Sport Psychologist, 13, 201-220.

John, O. P., \& Srivastava, S. (1999). The Big-Five trait taxonomy: History, measurement, and theoretical perspectives. In L. A. Pervin \& O. P. John (Eds.), Handbook of personality: Theory and research (Vol. 2, pp. 102-138). New York: Guilford Press. 
1 Jones, G., Swain, A., \& Hardy, L. (1993). Intensity and direction dimensions of competitive state anxiety and relationships with performance. Journal of Sport Sciences, 11, 525 532. doi: 10.1080/02640419308730023.

Judd, C. M., Kenny, D. A., \& McClelland, G. H. (2001). Estimating and testing mediation and moderation in within-participant designs. Psychological Methods, 6, 115-134. doi: 10.1037/1082-989X.6.2.115.

Kenow, L. J., \& Williams, J. M. (1992). Relationship between anxiety, self-confidence, and the evaluation of coaching behaviors. The Sport Psychologist, 6, 344-357

Krane, V. (1994). The Mental Readiness Form as a measure of competitive state anxiety. The Sport Psychologist, 8, 189-202.

Laborde, S., Brull, A., Weber, J., \& Anders, S. L. (2011). Trait emotional intelligence in sports: A protective role against stress through heart rate variability? Personality and Individual Differences, 51, 23-27. doi: 10.1016/j.paid.2011.03.003.

Martens, R., Burton, D., Vealey, R. S., Bump, L. A., \& Smith, D. E. (1990). Development and validation of the Competitive State Anxiety Inventory-2. In R. Martens, R. S.Vealey, \& D. Burton (Eds.), Competitive anxiety in sport (pp. 117-190). Champaign, IL: Human Kinetics.

Masters, R. S. W. (1992). Knowledge, knerves and know-how: The role of explicit versus implicit knowledge in the breakdown of a complex motor skill under pressure. British Journal of Psychology, 83, 343- 358. doi: 10.1111/j.2044-8295.1992.tb02446.x.

Mateo, M., Blasco-Lafarga, C., Martinez-Navarro, I., Guzman, J. F., Zabala, M. (2012). Heart rate variability and pre-competitive anxiety in BMX discipline. European Journal of Applied Physiology, 112, 113-123. doi: 10.1007/s00421-011-1962-8. 
1 Murray, N. P., \& Raedeke, T. D. (2008). Heart rate variability as an indicator of precompetitive arousal. International Journal of Sport Psychology, 39, 346-355.

3 O’Sullivan, D. M., Zuckerman, M., \& Kraft, M. (1998). Personality characteristics of male and female participants in team sports. Personality and Individual Differences, 25, 119-128. doi:10.1016/S0191-8869(98)00036-1.

Ormel, J., \& Wohlfarth, T. (1991). How neuroticism, long-term difficulties, and life situations change influence psychological distress: A longitudinal model. Journal of Personality \& Social Psychology, 60, 744-755. doi: 10.1037/0022-3514.60.5.744.

Oudejans, R. D., Binsch, O., \& Bakker, F. C. (2013). Negative instructions and choking under pressure in aiming at a far target. International Journal of Sport Psychology, 44, 294-309. ISSN 00470767.

Quintana, D. S., Heathers, J., \& Kemp A. H. (2012). On the validity of using the Polar RS800 heart rate monitor for heart rate variability research. European Journal of Applied Physiology, 112, 4179-4180. doi: 10.1007/s00421-012-2453-2

Rammstedt, B., \& John O. P. (2007). Measuring personality in one minute or less: A 10-item short version of the Big Five Inventory in English and German. Journal of Research in Personality, 41, 203-212. doi: 10.1016/j.jrp.2006.02.001

Robazza, C., Bortoli, L., \& Nougier, V. (2000). Performance emotions in an elite archer: A case study. Journal of Sport Behavior, 23, 144-163.

Roberts, R., \& Woodman, T. (2015). Contemporary personality perspectives in sport psychology. In S. Hanton and S. Mellalieu (Eds). Contemporary advances in sport psychology: A review (pp. 1-28). Oxford UK: Routledge.

Russell, C., \& Grealy, M. A. (2010). Avoidant instructions induce ironic and overcompensatory movement errors differently between and within individuals. 
Quarterly Journal of Experimental Psychology, 63, 1671-1682. doi:10.1080/17470210903572022.

Silva, J. M., Shultz, B. B., Haslam, R. W., Martin, T. P., \& Murray, D. F. (1985). Discriminating characteristics of contestants at the United States Olympic Wrestling Trials. International Journal of Sport Psychology, 16, 79-102.

Taylor, G. J., Bagby, R. M., \& Parker, J. D. A. (1997). Disorders of affect regulation: Alexithymia in medical and psychiatric illness. Cambridge, England: Cambridge University Press. doi:10.1002/1099-0879.

Tellegen, A. (1985). Structures of mood and personality and their relevance to assessing anxiety, with an emphasis on self-report. In A. H. Tuma \& J. D. Maser (Eds.), Anxiety and the anxiety disorders (pp. 681-706). Hillsdale, NJ: Eribaum.

Toner, J., Moran, A., Jackson, R. (2013). The effect of avoidant instructions on golf putting proficiency and kinematics. Psychology of Sport Exercise, 14, 501-507. 10.1016/j.psychsport.2013.01.008.

Watson, D., \& Clark, L. A. (1984). Negative affectivity: The disposition to experience aversive emotional states. Psychological Bulletin, 96, 465-490. doi: 10.1037/00332909.96.3.465.

Wegner, D. M. (1989). White bears and other unwanted thoughts. New York: Viking/Penguin.

Wegner, D. M. (1994). Ironic processes of mental control. Psychological Review, 101 , 34-52. doi:10.1037/0033-295X.101.1.34.

Wegner, D. M. (1997). Why the mind wanders. In J. D. Cohen \& J. W. Schooler (Eds.), Scientific approaches to consciousness (pp. 295-315). Mahwah, NJ: Erlbaum. 
1 Wegner, D. M. (2009). How to think, say, or do precisely the worst thing for any occasion. Science, 325, 48-50. doi:10.1126/science.1167346.

3

4

Wegner, D. M., Ansfield, M. E., \& Pilloff, D. (1998). The putt and the pendulum: Ironic effects of the mental control of action. Psychological Science, 9, 196-199.

Wegner, D. M., Erber, R., \& Zanakos, S. (1993). Ironic processes in the mental control of mood and mood-related thought. Journal of Personality and Social Psychology, 65, 1093-1104.

Weinberg, R. S., \& Gould, D. (2007). Foundations of sport and exercise psychology (4 ${ }^{\text {th }}$ Edition). Champaign, IL: Human Kinetics. doi: 10.1080/02640410701282405.

Williams, J. M., Jerome, G. J., Kenow, L. J., Rogers, T., Sartain. T. A., \& Darland, G. (2003) Factor structure of the coaching behavior questionnaire and its relationship to athlete variables. The Sport Psychologist, 17, 16-34.

Woodman, T., \& Davis, P. A. (2008). The role of repression in the incidence of ironic errors. The Sport Psychologist, 22, 184-197.

Woodman, T., \& Hardy, L. (2001). Stress and anxiety. In R. Singer, H. A. Hausenblas, and C.M. Janelle (Eds.). Handbook of research on sport psychology ( $2^{\text {nd }}$ ed., pp. 290-318). New York: Wiley.

Woodman, T., Barlow, M., \& Gorgulu, R. (2015). Don’t miss, don't miss, d'oh! Performance when anxious suffers specifically where least desired. The Sport Psychologist, 29, 213-223. doi: 10.1123/tsp.2014-0114.

Woodman, T., Hardy, L., Barlow, M., \& Le Scanff, C. (2010). Motives for prolonged engagement high-risk sports: An agentic emotion regulation perspective. Psychology of Sport and Exercise, 11, 345-352. doi:10.1016/j.psychsport.2010.04.002 
1 Woodman, T., Roberts, R., Hardy, L., Callow, N., \& Rogers, C. H. (2011). There is an "I" in TEAM: Narcissism and social loafing. Research Quarterly for Exercise and Sport, 82, 285-290. doi: 10.1080/02701367.2011.10599756.

4 Wright, R.A., Killebrew, K., \& Pimpalapure, D. (2002). Cardiovascular incentive effects 5 where a challenge is unfixed: Demonstrations involving social evaluation, evaluator status and monetary reward. Psychophysiology, 39, 188-197.

7 Zourbanos, N., Theodorakis, Y., \& Hatzigeorgiadis, A. (2006). Coaches’ behavior, social support and athletes' self-talk. Hellenic Journal of Psychology, 3, 117-133. 
1 Table 1. Regression results based on the Judd et al. (2001) procedure for testing within-subjects moderation in Study 1 and Study 2.

\begin{tabular}{|c|c|c|c|c|c|c|c|c|}
\hline & \multicolumn{4}{|c|}{ Study 1} & \multicolumn{4}{|c|}{ Study 2} \\
\hline & Mean (SD) hits & $b_{0}$ & $b_{1}$ & $t$ & Mean (SD) hits & $b_{0}$ & $b_{1}$ & $t$ \\
\hline \multicolumn{9}{|l|}{ Ironic performance error } \\
\hline Low-anxiety $\left(\hat{Y}_{1}\right)$ & $3.75(2.11)$ & 1.69 & $.06^{\mathrm{a}}$ & 1.38 & $2.16(1.74)$ & 3.58 & $-.21^{\mathrm{a}}$ & $2.32^{*}$ \\
\hline High-anxiety $\left(\hat{Y}_{2}\right)$ & $4.06(2.08)$ & 7.82 & $-.11^{\mathrm{a}}$ & $2.68^{* *}$ & $3.58(1.92)$ & 1.43 & $.36^{\mathrm{a}}$ & $3.75^{* * *}$ \\
\hline$\hat{Y}_{1}-\hat{Y}_{2}$ difference & $.31(2.53)$ & $6.13^{\mathrm{a}}$ & $-.17^{\mathrm{a}}$ & $3.52^{* *}$ & $1.42(2.73)$ & -2.12 & $.56^{\mathrm{a}}$ & $4.25^{* * *}$ \\
\hline \multicolumn{9}{|l|}{ Target hits } \\
\hline Low-anxiety $\left(\hat{Y}_{1}\right)$ & $11.12(2.94)$ & 15.73 & $-.14^{\mathrm{a}}$ & $2.29^{*}$ & $4.83(2.81)$ & 1.20 & $.56^{\mathrm{a}}$ & $4.09^{* * *}$ \\
\hline High-anxiety $\left(\hat{Y}_{2}\right)$ & $11.22(2.88)$ & 6.98 & $.12^{\mathrm{a}}$ & $2.15^{*}$ & $3.00(2.63)$ & 4.09 & $-.17^{\mathrm{a}}$ & -1.19 \\
\hline$\hat{Y}_{1}-\hat{Y}_{2}$ difference & $.10(2.97)$ & $-8.75^{\mathrm{a}}$ & $.26^{\mathrm{a}}$ & $4.90^{* * *}$ & $-1.83(2.94)$ & $2.89^{\mathrm{a}}$ & $-.73^{\mathrm{a}}$ & $-5.43^{* * *}$ \\
\hline \multicolumn{9}{|l|}{ Non-ironic error } \\
\hline Low-anxiety $\left(\hat{Y}_{1}\right)$ & $4.72(2.27)$ & 2.95 & $.05^{\mathrm{a}}$ & 1.10 & $7.30(2.93)$ & 7.39 & $-.01^{\mathrm{a}}$ & .09 \\
\hline High-anxiety $\left(\hat{Y}_{2}\right)$ & $4.51(2.32)$ & 5.44 & $-.03^{\mathrm{a}}$ & .57 & $7.58(2.55)$ & 6.88 & $.11^{\mathrm{a}}$ & .79 \\
\hline$\hat{Y}_{1}-\hat{Y}_{2}$ difference & $-.21(2.03)$ & $2.49^{\mathrm{a}}$ & $-.08^{\mathrm{a}}$ & 1.92 & $.28(2.50)$ & $-.51^{\mathrm{a}}$ & $.12^{\mathrm{a}}$ & .92 \\
\hline \multicolumn{9}{|l|}{ Arc-length $(\mathrm{cm})$} \\
\hline Low-anxiety $\left(\hat{Y}_{1}\right)$ & - & - & - & - & $2.34(1.82)$ & 2.70 & -.06 & -.57 \\
\hline High-anxiety $\left(\hat{Y}_{2}\right)$ & - & - & - & - & $3.61(1.69)$ & 2.33 & .19 & $2.11^{*}$ \\
\hline$\hat{Y}_{1}-\hat{Y}_{2}$ difference & - & - & - & - & $1.19(2.17)$ & -.43 & .25 & $2.08^{*}$ \\
\hline \multicolumn{9}{|l|}{ Radial error $(\mathrm{cm})$} \\
\hline Low-anxiety $\left(\hat{Y}_{1}\right)$ & - & - & - & - & $6.68(3.10)$ & 7.84 & -.19 & -1.07 \\
\hline High-anxiety $\left(\hat{Y}_{2}\right)$ & - & - & - & - & $8.72(2.75)$ & 7.02 & .26 & 1.71 \\
\hline$\hat{Y}_{1}-\hat{Y}_{2}$ difference & - & - & - & - & $1.86(3.58)$ & -1.27 & .49 & $2.47^{*}$ \\
\hline
\end{tabular}

Notes: $b_{0}=\mathrm{Y}$ intercept; $b_{1}=$ Unstandardized beta coefficient; Based on the Judd et al. (2001) within-subjects moderation procedure, a significant $\hat{Y}_{1}-\hat{Y}_{2}$ difference score is evidence that neuroticism is a significant moderator.

${ }^{*} p<.05$

${ }^{* * *} p<.01$,

${ }^{* * * *} p<.001$

${ }^{a}=$ The $b_{1}$ values between Study 1 and Study 2 have opposite values because we assessed neuroticism using Goldberg's (1999) IPEP measure of emotional stability in Study 1 (high scores reflect low neuroticism) and we assessed neuroticism using Rammstedt and John's (2007) BFI-10 neuroticism factor in Study 2 (high scores reflect high neuroticism). 
Figure 1. The ironic error, target, and non-ironic error zones for the football penalty-shooting task in Study 1.

Note: The thick dashed line represents two ropes that delimited both the target and non-ironic error zones. The ironic error zone was delimited by a cone. A mirrored set-up was used for left-footed participants.

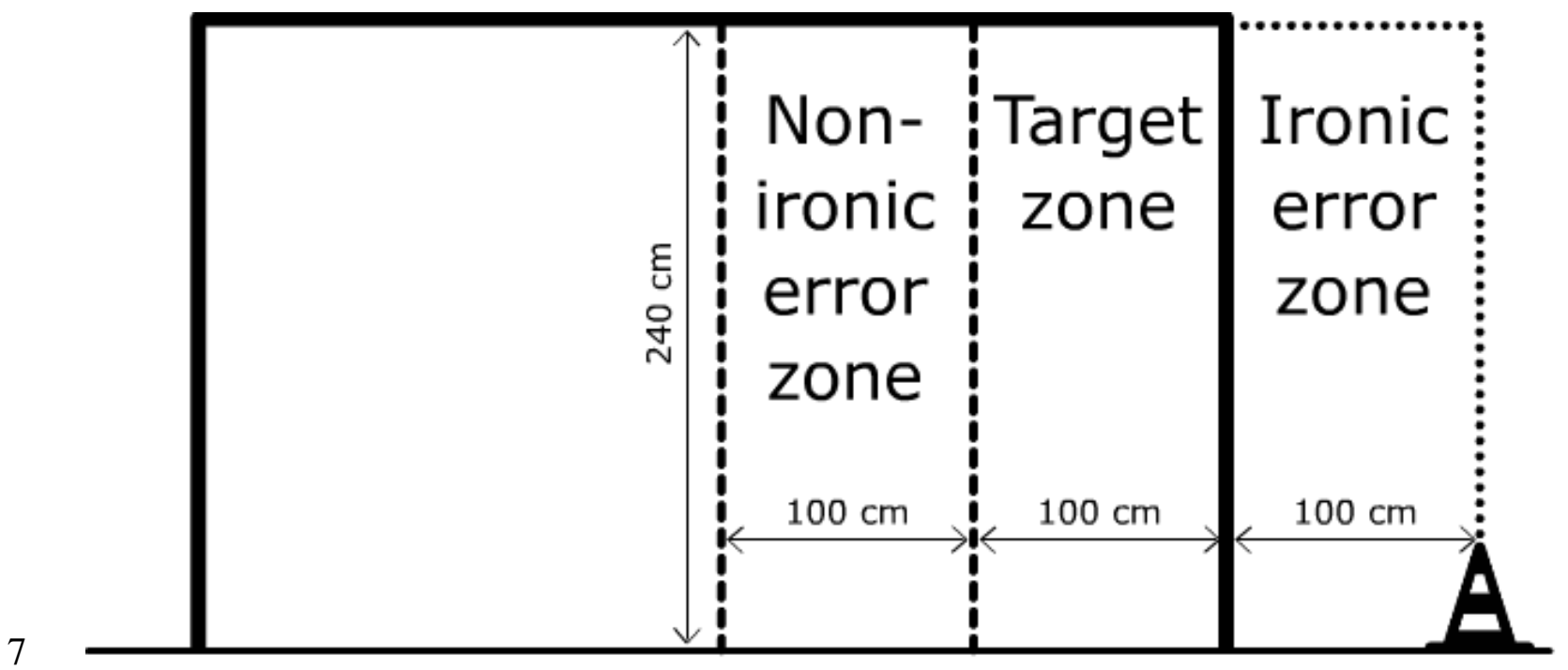


Figure 2. Regression slopes for performance (ironic error hits, target hits, non-ironic error hits) regressed on neuroticism in Study 1 and Study 2 as presented in Table 1; a significant neuroticism $\mathrm{x}$ anxiety interaction for ironic error hits and target hits (top two graphs) but not for non-ironic error hits (bottom graph).

5
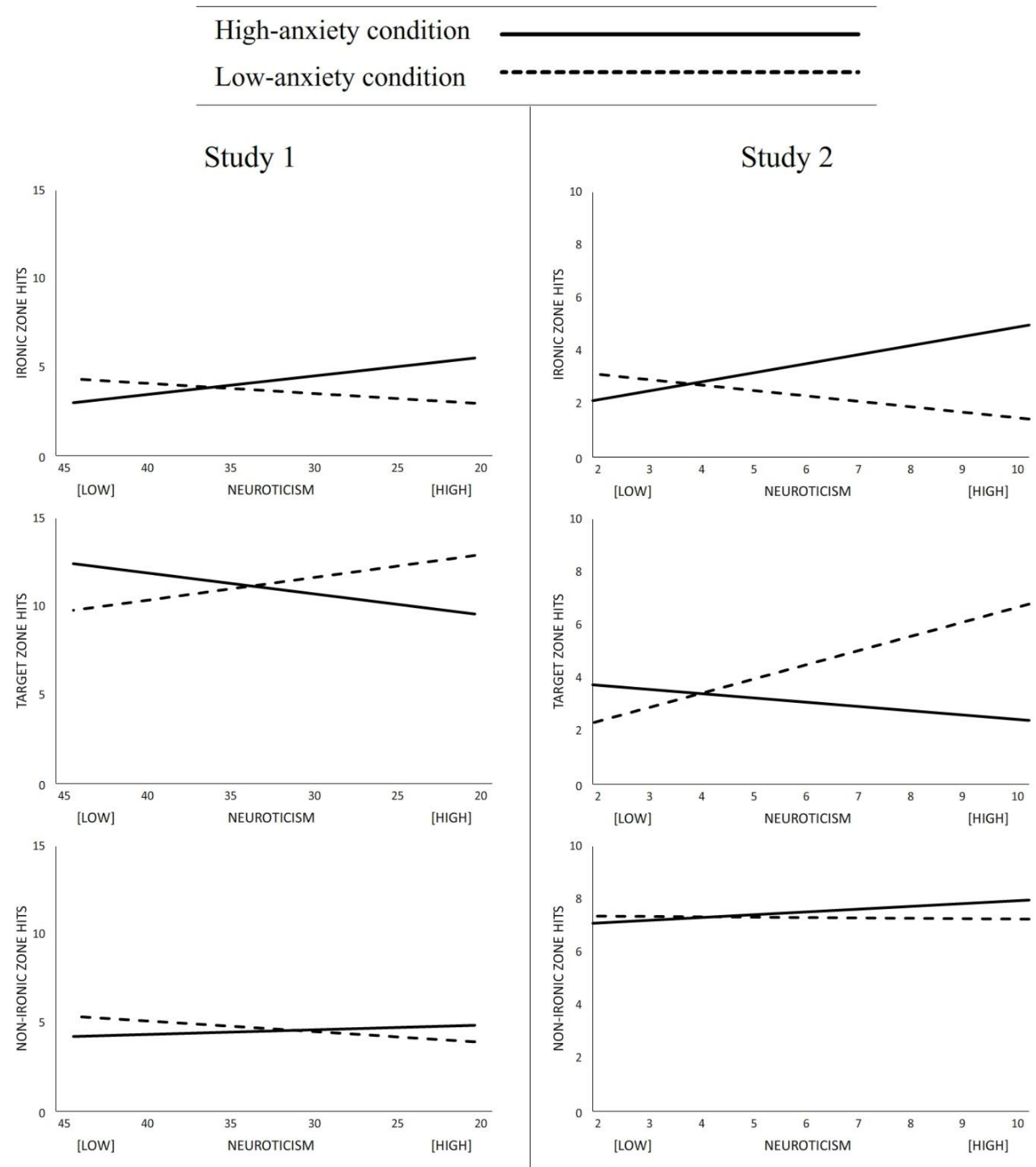
Figure 3. The dart throwing task target.

2 Note: The dart board cover sheet indicates the available scores based on proximity of the dart 3 to the central target zone, which was worth nine points. The designated ironic error zone was 4 one of the four quadrants (e.g., top right quadrant) and was balanced across participants. We 5 informed participants that hits landing in the designated ironic error zone would score zero 6 points regardless of the proximity to the target zone. This figure is reproduced with 7 permission of Woodman et al. (2015).

9

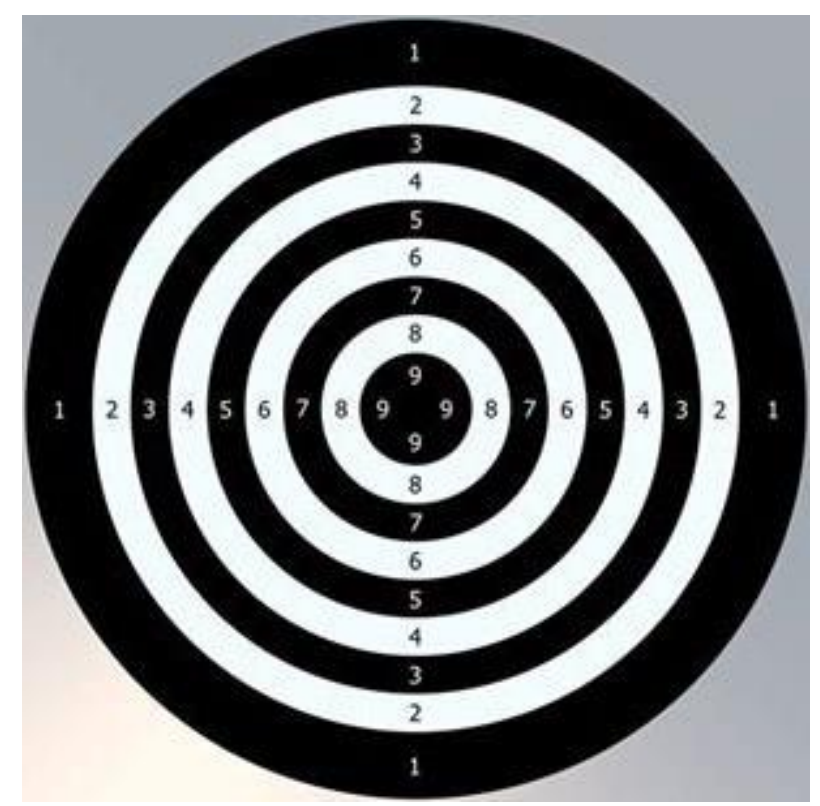


Figure 4. The measurement of arc-length and radial error in the Study 2 dart throwing task. Note. The quadrant represents the ironic error zone. The points that are labeled 1 and 2 represent two hypothetical dart strikes, which have landed within the ironic error zone. We consider Dart 1 to be precisely more ironic than Dart 2 because it has both a greater arclength ( $\mathrm{a}$; the arc-length from the closest non-ironic error zone) and a greater radial error $(\mathrm{b}$; the radial distance from the target zone $\mathrm{c}$ ). This figure is reproduced with permission of Woodman et al. (2015).

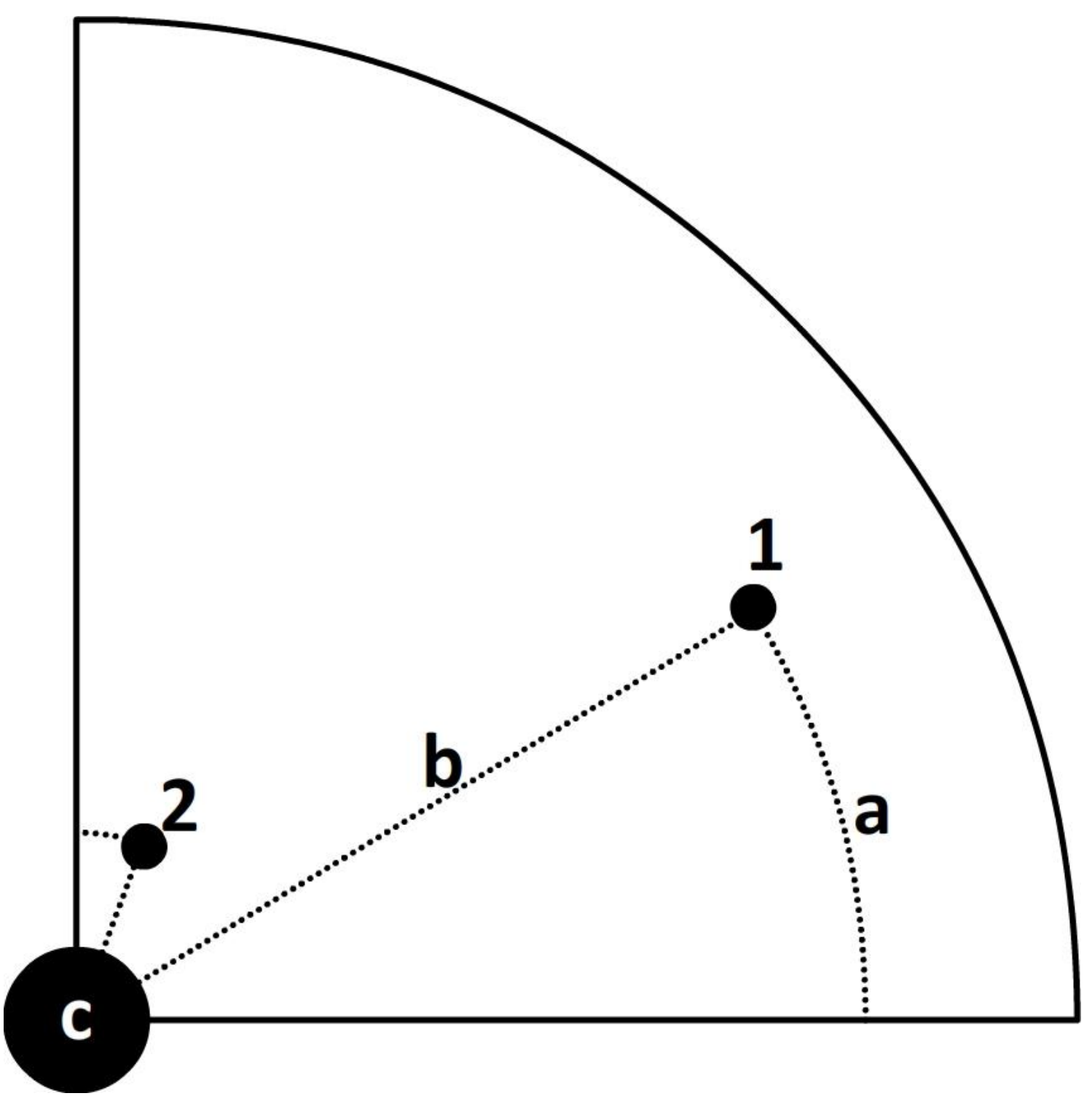

\section{Highlights}

- Across two studies we examined Wegner's theory of ironic processes of mental control

- We used ecologically valid performance tasks and ecologically valid performance stressors

- We provide the first evidence that neuroticism moderates ironic performance error

- Neuroticism moderates the incidence of ironic performance error when anxious

- Neuroticism moderates the precision of irony of ironic error when anxious 